\title{
The Clinicopathological Characteristics of Palpable and Non-palpable Breast Cancer
}

\author{
Dongju Kim, M.D., Ph.D. ${ }^{1}$, Soo Jung Lee, M.D., Ph.D. ${ }^{2}$, Byung Kyun Ko, M.D., Ph.D. ${ }^{3}$, \\ Han-Byoel Lee, M.D., Ph.D. ${ }^{4}$, Jung Han Yoon, M.D., Ph.D. ${ }^{5}$, Seok Won Lee, M.D., Ph.D. ${ }^{6}$, \\ Ye Won Jeon, M.D., Ph.D. ${ }^{7}$, Bong Kyun Kim, M.D., Ph.D. ${ }^{1}$, Jina Lee, M.D. ${ }^{1}$, Woo Young Sun, M.D., Ph.D. ${ }^{1}$ \\ ${ }^{1}$ Department of Surgery, Daejeon St. Mary's Hospital, College of Medicine, The Catholic University of Korea, Seoul; ${ }^{2}$ Department of Surgery, \\ Yeungnam University Medical Center, Deagu; ${ }^{3}$ Department of Surgery, Ulsan University Hospital, Ulsan; ${ }^{4}$ Department of Surgery, Seoul National \\ University College of Medicine, Seoul; ${ }^{5}$ Department of Surgery, Chonnam National University Hwasun Hospital, Hwasun; ${ }^{6}$ Department of Surgery, \\ Pusan National University Hospital, Busan; 'Department of Surgery, The Catholic University of Korea St. Vincent's Hospital, Suwon, Korea
}

Purpose: Palpability is known to be a poor prognostic factor for breast cancer. The present study analyzed the clinicopathological characteristics and outcomes of palpable and nonpalpable breast cancers using big data. Methods: Between January 2005 and May 2019, a total of 15,141 patients were enrolled. All patients were diagnosed with invasive ductal carcinomas. Patients with unclear medical records, multiple tumors, bilateral breast cancers, inflammatory breast cancers, inoperable breast cancers and distant metastasis were excluded. Patients were divided into the palpable and nonpalpable breast cancer groups based on physicians' clinical examinations. The clinicopathological characteristics and disease-specific survivals (DSS) were analyzed. Results: Patients with palpable breast cancers were younger, had larger tumors, and higher tumor-node-metastasis stage $(p<0.001)$ than patients with nonpalpable breast cancers. Palpable breast cancer cases had higher rates of lympho-vascular invasion, higher histologic and nuclear grades than nonpalpable breast cancer cases $(p<0.001)$. The positive proportion of hormone receptor was higher in the nonpalpable breast cancer group than in the palpable breast cancer group, but that of human epidermal growth factor receptor 2 was higher in the palpable breast cancer group than in the nonpalpable breast cancer group $(p<0.001)$. The Ki-67 index was higher in the palpable breast cancer group than in the nonpalpable breast cancer group $(p<0.001)$. Total mastectomy and axillary dissection were performed more frequently in the palpable breast cancer group than in the nonpalpable breast cancer group $(p<0.001)$. Adjuvant chemotherapy was administered more frequently in the palpable breast cancer group than in the nonpalpable breast cancer group. However, radiotherapy and hormonal therapy were performed more frequently in nonpalpable breast cancer group than in the nonpalpable breast cancer group $(p<0.001)$. According to a multivariate analysis, younger age, lower body mass index, larger tumor size, tumor location, higher stage, higher histologic grade and higher Ki-67 index were associated with palpability $(p<0.001)$. DSS was significantly lower in the palpable breast cancer group than in the nonpalpable breast cancer group $(p<0.001)$. Conclusion: Palpable breast cancers tend to be triple negative breast cancers and have higher histologic grade and, Ki-67 index and worse prognosis than nonpalpable breast cancers. Therefore, based on the results of the present study, treating palpable breast cancers requires careful attention.

Key Words: Breast neoplasms, Carcinoma, Palpation

\section{INTRODUCTION}

The invigoration of screening programs and the development of radiologic diagnosis have reduced the importance of physical breast examination. A randomized study showed that screening leads to a decrease in breast cancer mortality rate of approximately $20 \%$ [1,2]. On the contrary, several findings regarding screening exist. Screening might be associated with overdiagnosis and overtreatment $[1,3,4]$. In

Correspondence: Woo Young Sun, M.D., Ph.D.

Department of Surgery, Daejeon St. Mary's Hospital, College of Medicine, The Catholic University of Korea, 64 Daeheung-ro, Jung-gu, Daejeon 34943, Korea Tel: +82-42-220-9235, Fax: +82-42-220-9565, E-mail: sun2729@catholic.ac.kr Received: Dec 27, 2019 Revised: Feb 14, 2020 Accepted: Jul 1, 2020 most cases, breast cancers are detected before they become clinically apparent through radiologic examinations, and the survival rates of patients with radiologically detected breast cancers have improved [57]. However, the majority of the diagnosed breast cancers are palpable breast cancers. Generally, palpable breast cancers are considered aggressive and advanced. However, palpability is a completely different concept from tumor size when establishing the diagnosis of breast cancer. Although, cancers detected at screening are smaller in size than clinically apparent cancers in principle, it is not always the case. It is true that some small cancers can be palpable, while some large cancers can be nonpalpable, and vice versa. Despite several factors observed for palpable cancers, palpable and nonpalpable breast cancers are fun- 
damentally different.

Our study aimed to identify the differences in clinicopathological characteristics and clinical outcomes between palpable and nonpalpable breast cancers.

\section{METHODS}

\section{Data collection}

The clinical information of patients who were diagnosed with breast cancers was obtained from Korean Breast Cancer Society registration system (KBCR). The KBCR has been registered breast cancer cases by breast cancer surgeons from 110 training hospitals nationwide since $1996[8,9]$. The cause and date of death in these data were used in connection with the data of the Korea Central Cancer Registry (Ministry of Health and Welfare in collaboration with the Korean National Statistical Office) to compile complete death statistics which were updated through 2014. This study was approved by the Institutional Review Board of our hospital (IRB No. DC19RESI0073).

\section{Patient and clinical characteristics}

Between January 2005 and May 2019, the data of 18,575 patients from the original database were analyzed. All patients were diagnosed with invasive ductal carcinomas and received surgical treatment initially. Moreover, 3,434 patients were excluded for the following reasons: patients had unclear medical records, patients received neoadjuvant chemotherapy or radiotherapy, and patients had multiple tumors, cancers in both breasts, inflammatory breast cancers, inoperable breast cancers and distant metastasis. A total of 15,141 patients were analyzed (Figure 1). The patients were divided into the palpable breast cancer $(\mathrm{n}=11,364)$ and nonpalpable breast cancer groups $(\mathrm{n}=3,777)$. Palpability was determined by doctor's physical examination before surgical treatment and nonpalpable breast cancer was defined as a tumor detected by screening radiologic examination. The data of the following parameters were collected: age at diagnosis; body mass index (BMI); family history of breast cancer; tumor palpability; tumor size; tumor location; histologic types; T stage; $\mathrm{N}$ stage; pathologic stage; lymphovascular invasion; histologic and nuclear grade; estrogen receptor (ER), progesterone receptor (PgR), and human epidermal growth factor receptor 2 (HER-2) receptor status; Ki-67 index; type of treatment; and outcome. Pathologic stages were determined based on the postoperative pathologic stages according to the American Joint Committee on Cancer AJCC 2017 guidelines. The histologic subtype was divided into invasive ductal carcinoma and other types and lymph node status was evaluated using sentinel lymph node biopsy and/or axillary dissection. The subtype was divided based on hormone receptor and HER-2 receptor status, and triple-negative breast cancer (TNBC) was defined as negative hormone and HER-2 receptor. The surgical treatment methods were breast-conserving surgery (BCS) and mastectomy. Disease-specific survival (DSS) was analyzed to assess clinical outcomes. Clinicopathological characteristics and outcomes of both groups were analyzed.

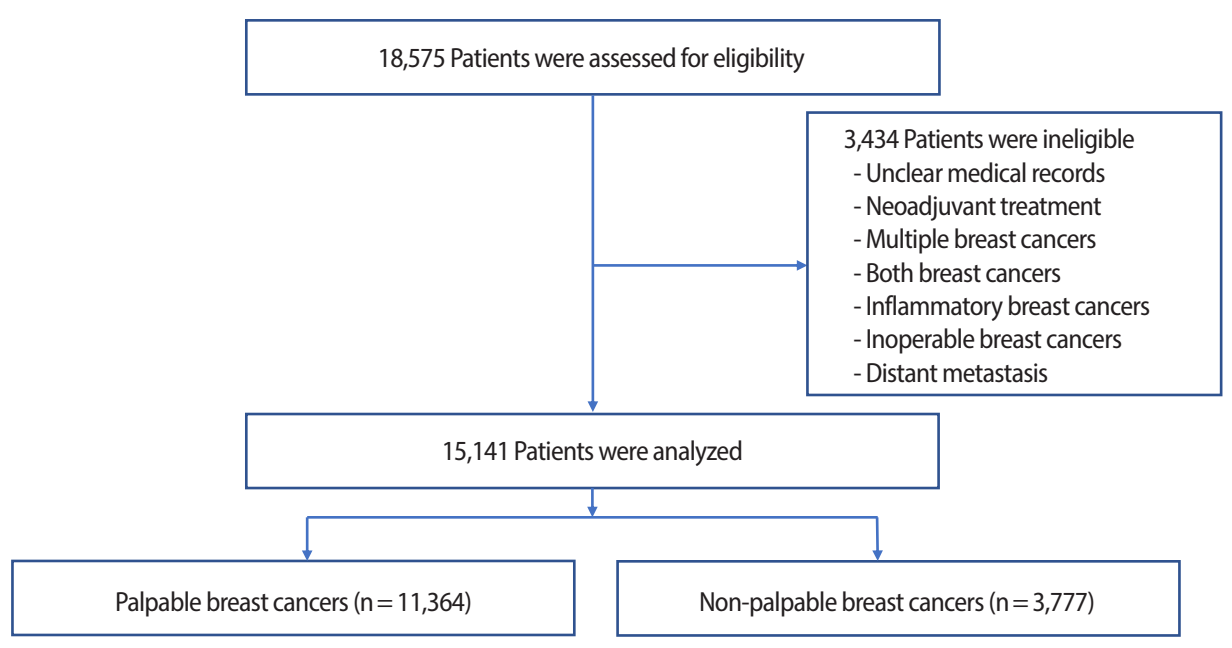

Figure 1. Study population. 


\section{Statistical analyses}

Univariate and multivariate analyses were performed. The clinicopathological difference between the groups was analyzed using student's t-test, chi-square test and logistic regression analysis. Moreover, Kaplan-Meier analysis was used for DSS. The statistical package for the social sciences version 22.0 (International Business Machines Corp., Armonk, NY, USA) was used as the statistical program and $p<0.05$ was considered to indicate statistical significance.

\section{RESULTS}

\section{Patient and tumor characteristics}

According to the univariate analysis of clinical characteristics, the mean age of patients with palpable breast cancer was 50.87 years-, which was significantly lower than that of patients with nonpalpable breast cancers $(50.88 \pm 10.92$ years [palpable] vs. $52.15 \pm 10.14$ years [nonpalpable], $p<0.001)$. The BMI was lower in the palpable breast cancer group than in the nonpalpable breast cancer group $(23.62 \pm 3.44$ [palpable] vs. $23.68 \pm 3.27$ [nonpalpable], $p=0.012$ ), Furthermore, palpable breast cancers were larger than nonpalpable breast cancers $(2.05 \pm 1.20$ $\mathrm{cm}$ [palpable] vs. $1.24 \pm 0.85 \mathrm{~cm}$ [nonpalpable], $p<0.001)$. The laterality of tumor was not different in both groups (left:right (\%), 50.9:49.1 [palpable] vs. 50.6:49.4 [non-palpable], $p=0.805$ ). However, the tumor location was different in either groups. The nonpalpable breast cancers were frequently located in the upper outer (UO) portion of the breast $(p<0.001)$. A higher number of patients with nonpalpable breast cancers had a family history of breast cancer than that among patients with palpable breast cancers, and the difference was insignificant $(10.6 \%$ [palpable] vs. 11.7\% [nonpalpable], $p=0.053)($ Table 1$)$.

\section{Pathological characteristics}

Patients with palpable tumors had higher T stages and higher rates of lymph node involvement than patients with nonpalpable tumors. The percentages of $\mathrm{T} 1$ stages in the nonpalpable breast cancer and palpable breast cancer groups were $81.2 \%$ and $54.9 \%$, respectively. The percentages of $\mathrm{T} 2$ stages in the nonpalpable breast cancer and palpable breast cancer groups were $11.5 \%$ and $39.8 \%$ respectively. The difference between groups was significant $(p<0.001)$. Even regarding $\mathrm{N}$ stages, the palpable breast cancer group had higher $\mathrm{N}$ stages than the nonpalpable breast cancer group. In the nonpalpable breast cancer
Table 1. Patient's and clinical characteristics of palpable vs. nonpalpable breast cancer

\begin{tabular}{lccr}
\hline Characteristic & $\begin{array}{c}\text { Palpable } \\
(\mathrm{n}=11,364) \\
\text { No. }(\%)\end{array}$ & $\begin{array}{c}\text { Nonpalpable } \\
(\mathrm{n}=3,777) \\
\text { No. }(\%)\end{array}$ & $p$-value \\
\hline Age (mean) & 50.88 & 52.15 & $<0.001$ \\
BMI (mean) & 23.62 & 23.68 & 0.012 \\
Family breast cancer & $1,200(10.6)$ & $442(11.7)$ & 0.053 \\
History (+) & & & \\
Size (cm) & 2.05 & 1.24 & $<0.001$ \\
Laterality (left:right) & $5,779(50.9):$ & $1,912(50.6):$ & 0.805 \\
& $5,585(49.1)$ & $1,865(49.4)$ & \\
Location of tumor & & & $<0.001$ \\
UO & $5,942(52.2)$ & $2,116(56.0)$ & \\
UI & $2,421(21.3)$ & $766(20.3)$ & \\
LO & $1,449(12.8)$ & $468(12.4)$ & \\
LI & $712(6.3)$ & $217(5.7)$ & \\
C & $840(7.4)$ & $210(5.6)$ & \\
\hline
\end{tabular}

$\mathrm{BMI}=$ body mass index; $\mathrm{UO}=$ upper outer $\mathrm{UI}=$ upper inner; $\mathrm{LO}=$ lower out er; $\mathrm{LI}=$ lower inner; $\mathrm{C}=$ central.

group, N0, Nmic, N1, N2, and N3 stages were observed 80.4\%, 3.2\%, $13.1 \%, 2.3 \%$, and $1.1 \%$ of patients, respectively. In the palpable breast cancer groups, N0, Nmic, N1, N2, and N3 stages were observed 66.1\%, $3.2 \%, 21.7 \%, 6.0 \%$, and $3.0 \%$ of patients, respectively $(p<0.001)$. These differences also resulted in differences in stages of both groups. In the nonpalpable breast cancer group, the percentages of stage I, II, and III were $76.8 \%, 19.8 \%$, and $3.5 \%$, respectively. The stage was higher in the palpable breast cancer group than in the nonpalpable breast cancer group. In the palpable breast cancer group, the percentages of stage I, II, and III were $45.9 \%, 44 \%$, and 9.8\%, respectively. Furthermore, the results were significant $(p<0.001)$. Palpable breast cancers tended to invade the lymphatic and vascular systems significantly. The lymphatic and vascular invasions were $33.3 \%$ and $22.9 \%$ in the palpable breast cancer groups and $18.0 \%$ and $11.0 \%$ in the nonpalpable breast cancer group, respectively $(p<0.001)$. Additionally, palpable tumors were more likely to be poorly differentiated and exhibit a significant high nuclear grade compared with nonpalpable tumors. The percentages of low, intermediate, and high histologic grade in the nonpalpable breast cancer group were $20.9 \%, 57.1 \%$, and $22.0 \%$ respectively. The percentages of low and high histologic grade in the palpable breast cancer group were $10.6 \%$ and $39.3 \%$, respectively $(p<0.001)$. Similarly, the percentages of low and high nuclear grade in the nonpalpable breast cancer group were $11.4 \%$ and $25.8 \%$, respectively. The percentages of low and high nuclear grade in the palpable breast cancer group were 
Table 2. Pathological characteristics of palpable vs. nonpalpable breast cancer

\begin{tabular}{|c|c|c|c|}
\hline Characteristic & $\begin{array}{c}\text { Palpable } \\
(\mathrm{n}=11,364) \\
\text { №. }(\%)\end{array}$ & $\begin{array}{c}\text { Nonpalpable } \\
(n=3,777) \\
\text { No. }(\%)\end{array}$ & $p$-value \\
\hline Tstage & & & $<0.001$ \\
\hline Tmic & $325(2.9)$ & $261(6.9)$ & \\
\hline $\mathrm{T} 1$ & $6,235(54.9)$ & $3,068(81.2)$ & \\
\hline $\mathrm{T} 2$ & $4,527(39.8)$ & $433(11.5)$ & \\
\hline T3 & $250(2.2)$ & $13(0.3)$ & \\
\hline T4 & $27(0.2)$ & $2(0.1)$ & \\
\hline N stage & & & $<0.001$ \\
\hline No & $7,506(66.1)$ & $3,038(80.4)$ & \\
\hline Nmic & $364(3.2)$ & $120(3.2)$ & \\
\hline $\mathrm{N} 1$ & $2,466(21.7)$ & $493(13.1)$ & \\
\hline N2 & $684(6.0)$ & $86(2.3)$ & \\
\hline N3 & $344(3.0)$ & $40(1.1)$ & \\
\hline Stage & & & $<0.001$ \\
\hline I & $5,211(45.9)$ & $2,899(76.8)$ & \\
\hline ॥ & $5,037(44.3)$ & $746(19.8)$ & \\
\hline III & $1,116(9.8)$ & $132(3.5)$ & \\
\hline Lymphatic invasion (+) & 3,781 (33.3) & $681(18.0)$ & $<0.001$ \\
\hline Vascular invasion (+) & $2,602(22.9)$ & $417(11.0)$ & $<0.001$ \\
\hline Histologic grade & & & $<0.001$ \\
\hline Low & $1,204(10.6)$ & 788 (20.9) & \\
\hline Intermediated & $5,694(50.1)$ & $2,158(57.1)$ & \\
\hline High & $4,466(39.3)$ & $831(22.0)$ & \\
\hline Nuclear grade & & & $<0.001$ \\
\hline Low & $583(5.1)$ & 431 (11.4) & \\
\hline Intermediated & $6,132(54.0)$ & $2,372(62.8)$ & \\
\hline High & $4,649(40.9)$ & $974(25.8)$ & \\
\hline Histologic type & & & 0.682 \\
\hline IDC & $10,599(93.3)$ & $3,530(93.5)$ & \\
\hline Other types & $765(6.7)$ & $247(6.5)$ & \\
\hline
\end{tabular}

IDC = invasive ductal carcinoma.

$5.1 \%$ and over $40.9 \%$, respectively, with a significant difference $(p<0.001)$ (Table 2). The histologic subtypes of the palpable and nonpalpable breast cancer groups were insignificantly different $(p=0.682)$ (Table 2$)$.

\section{Hormone receptor, HER-2 receptor status and $\mathrm{Ki}-67$ index}

Significant differences were observed in the hormone receptor and HER-2 receptor status in both groups. Nonpalpable breast cancers tended to be ER- and/or PR-positive and HER-2-negative subtype, and palpable breast cancers tended to be TNBCs. ER- and/or PR-positive and HER-2-negative subtype were observed in 70.9\% of nonpalpable breast cancers, and only $9.1 \%$ of patients had TNBCs. In case of palpable breast cancer, ER- and/or PR-positive and HER-2-negative subtype were observed in $59.2 \%$ of palpable breast cancers and $17.0 \%$
Table 3. Hormone receptor, human epidermal growth factor receptor 2 status, and Ki-67 index

\begin{tabular}{|c|c|c|c|}
\hline Characteristic & $\begin{array}{c}\text { Palpable } \\
(\mathrm{n}=11,364) \\
\text { No. }(\%)\end{array}$ & $\begin{array}{c}\text { Nonpalpable } \\
(n=3,777) \\
\text { No. }(\%)\end{array}$ & $p$-value \\
\hline Subtype & & & $<0.001$ \\
\hline ER and/or PgR(+) HER2(+) & $1,445(12.7)$ & $394(10.4)$ & \\
\hline ER and/or PgR(+) HER2(-) & $6,722(59.2)$ & $2,679(70.9)$ & \\
\hline ER and PgR(-) HER2(+) & $1,270(11.2)$ & $359(9.5)$ & \\
\hline ER and PgR(-) HER2(-) & $1,927(17.0)$ & $345(9.1)$ & \\
\hline Ki-67 Index & & & $<0.001$ \\
\hline Ki-67 (mean) & 27.65 & 18.47 & \\
\hline
\end{tabular}

$\mathrm{ER}=$ estrogen receptor; $\mathrm{PgR}=$ progesterone receptor; HER-2 = human epidermal growth factor receptor 2 .

of patients had TNBCs with a significant difference $(p<0.001)$. Additionally, the Ki-67 index, which is associated with tumor aggressiveness, was higher in the palpable breast cancer group than in the nonpalpable breast cancer group $(27.65 \pm 24.69$ [palpable] vs. $18.47 \pm 20.64$ [nonpalpable], $p<0.001$ ) (Table 3).

\section{Operation and postoperative management}

BCS was performed less frequently in patients with palpable tumors than in patients with nonpalpable tumors. Moreover, $78.9 \%$ of nonpalpable breast cancer patients underwent BCS, and $68.7 \%$ of palpable breast cancer patients underwent BCS $(p<0.001)$. Additionally, axillary dissection was less likely to be performed in the nonpalpable breast cancer group than in the palpable breast cancer group (23.9\% [nonpalpable] vs. $36.6 \%$ [palpable], $p<0.001$ ). Finally, patients with nonpalpable tumors were less likely to receive adjuvant chemotherapy than patients with palpable tumors (41.6\% [nonpalpable] vs. 66.8\% [palpable]). On the contrary, radiation and hormonal therapy were more likely to be performed in patients with nonpalpable breast cancers than in patients with palpable breast cancers $(79.1 \%$ and $80.3 \%$ [nonpalpable] vs. $73.5 \%$ and $70.8 \%$ [palpable]). This is possibly because patients with nonpalpable breast cancers tended undergo BCS and have hormone receptor-positive cancers than patients with palpable breast cancers (Table 4).

\section{Multivariate analysis for clinical factors associated with palpability}

According to a multivariate analysis, younger age; lower BMI; larger size; tumor location in the upper inner, lower outer, or lower inner; 
Table 4. Surgical treatment and postoperative management

\begin{tabular}{|c|c|c|c|}
\hline Characteristic & $\begin{array}{c}\text { Palpable } \\
(n=11,364) \\
\text { No. }(\%)\end{array}$ & $\begin{array}{c}\text { Nonpalpable } \\
(n=3,777) \\
\text { No. }(\%)\end{array}$ & $p$-value \\
\hline Operation methods & & & $<0.001$ \\
\hline Breast conservation surgery & $7,810(68.7)$ & 2,981 (78.9) & \\
\hline Total mastectomy & $3,554(31.3)$ & $796(21.1)$ & \\
\hline Axillary evaluation & & & $<0.001$ \\
\hline SLNB & $7,203(63.4)$ & $2,875(76.1)$ & \\
\hline$A D$ & $4,161(36.6)$ & $902(23.9)$ & \\
\hline \multicolumn{4}{|l|}{ Adjuvant Treatment } \\
\hline Chemotherapy (+) & $7,593(66.8)$ & $1,573(41.6)$ & $<0.001$ \\
\hline Radiotherapy (+) & $8,353(73.5)$ & $2,986(79.1)$ & $<0.001$ \\
\hline Hormonal therapy (+) & $8,044(70.8)$ & $3,035(80.4)$ & $<0.001$ \\
\hline
\end{tabular}

$\mathrm{SLNB}=$ sentinel lymph node biopsy; $\mathrm{AD}=$ axillary dissection.

Table 5. Multivariate analysis for clinical factors associated with palpability

\begin{tabular}{lccc}
\hline Clinical factor & OR & $95 \% \mathrm{Cl}$ & $p$-value \\
\hline Age $(\geq 48)$ & 0.440 & $0.199-0.974$ & $<0.001$ \\
BMI $(\geq 23)$ & 0.970 & $0.947-0.979$ & $<0.001$ \\
Size $(\geq 20 \mathrm{~mm})$ & 4.894 & $2.117-2.495$ & $<0.001$ \\
Tumor location & & & $<0.001$ \\
UO & 0.736 & $0.651-0.831$ & \\
UI & 1.189 & $1.073-1.318$ & \\
LO & 1.090 & $0.963-1.234$ & \\
LI & 1.186 & $1.000-1.408$ & \\
C & 1.095 & $0.919-1.305$ & \\
Stage & & & 0.006 \\
I & reference & & \\
II & 1.244 & $1.085-1.427$ & \\
III & 1.245 & $0.991-1.563$ & \\
Histologic Grade & & & $<0.001$ \\
Grade 1 & reference & & \\
Grade 2 & 1.263 & $1.130-1.413$ & \\
Grade 3 & 1.644 & $1.417-1.908$ & \\
Ki-67 ( $\geq 14)$ & 1.996 & $1.014-1.017$ & $<0.001$ \\
\hline
\end{tabular}

$\mathrm{OR}=$ odds ratio; $\mathrm{Cl}=$ confidence interval; $\mathrm{BMI}=$ body mass index; $\mathrm{UO}=$ upper outer; $\mathrm{UI}=$ upper inner; $\mathrm{LO}=$ lower outer; $\mathrm{LI}=$ lower inner; $\mathrm{C}=$ Central.

high histologic grade, higher Ki-67 index were associated with palpability $(p<0.001)$. Moreover, higher stage breast cancer was considered a more palpable than nonpalpable breast cancer $(p=0.006)$ (Table 5).

\section{Survival analysis}

After a mean follow up of 80 months, the 10-year DSS was significantly lower in the palpable breast cancer group than that in the nonpalpable breast cancer group ( $98.1 \%$ [nonpalpable] vs. $96.0 \%$ [palpable], $p<0.001$ ) (Figure 2).

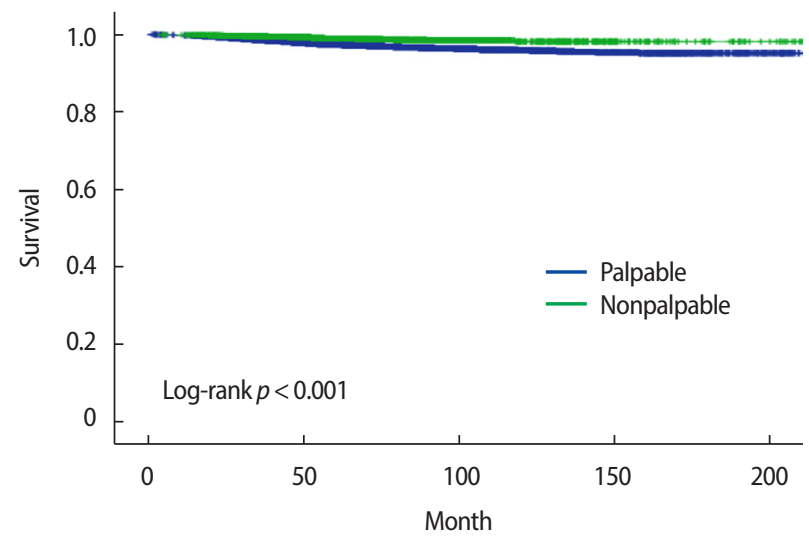

\begin{tabular}{lccc}
\hline & $\begin{array}{c}\text { Palpable breast } \\
\text { cancer }\end{array}$ & $\begin{array}{c}\text { Non-palpable } \\
\text { breast cancer }\end{array}$ & $p$-value \\
\hline 10 -yr DSS & 96.0 & 98.1 & $<0.001$ \\
\hline
\end{tabular}

Figure 2. Disease-specific survival of palpable vs. nonpalpable breast cancer.

\section{DISCUSSION}

Palpable breast cancer was generally considered an undefined advanced tumor. Few studies have reported the differences between palpable and nonpalpable breast cancers. In one study, palpable breast cancers diagnosed as the $\mathrm{T} 1$ stage showed significant differences when compared with nonpalpable breast cancers [10]. Patients with nonpalpable breast cancers had significantly better survival than patients with palpable breast cancers. However, when controlling for tumor size, this difference was insignificant. Another study reported that in a group of hormone receptor-positive and early-stage breast cancer patients, palpability was considered as an independent factor of tumor aggressiveness [11]. Palpable breast cancers had more aggressive features higher metastatic potential, higher incidence of breast cancer-related events and worse overall survival than nonpalpable breast cancers. In these previous studies only small-sized breast cancers were analyzed. It is true that palpability is closely associated with tumor size, it is not always the case. As previously stated, owing to several factors such as breast volume and density, some significantly small and large cancers are palpable, and not palpable respectively.

The present study analyzed all subjects who were diagnosed with breast cancer and who received breast surgery for primary treatment. We identified that the palpable breast cancer group had more aggressive and poorly differentiated cancers than the nonpalpable breast cancer group. Additionally, we identified that palpable breast cancers had 
worse clinical outcomes than nonpalpable breast cancers.

According to a multi-variated analysis, T stages were not different between the groups. However, palpable breast cancers had higher histologic grade and Ki-67 index than nonpalpable breast cancers. It is possibly attributed to the fact that palpability is a completely different concept from tumor size.

Interestingly, palpable breast cancers were more frequently observed in younger patients than in nonpalpable breast cancers, it might be possibly attributed to tumor density. However, further studies are required to confirm this hypothesis. Additionally, tumor location was different in both groups. Nonpalpable breast cancers were more frequently observed in the UO quadrant, probably because the UO quadrant has more breast tissues than the other quadrants.

Lower BMI was associated with palpability. BMI has been reported to influence both palpability and prognosis in breast cancer. It is well known that overweight is considered a poor prognostic factor of breast cancer. However, underweight can also be a poor prognostic factor $[12,13]$. In the present study, the direct association between BMI and the outcome was not evaluated. However, BMI was closely associated with palpability which correlated with poor outcomes in breast cancers. Additionally, breast cancers in patients with low BMI are likely to be palpable.

Several studies have shown that palpable breast cancers tended to involve the axillary node independent of tumor size [10,14-16]. Silverstein et al. reported that palpability was an independent factor for axillary nodal involvement in small breast cancers, and the rate of nodal metastasis was significantly higher in palpable breast cancers than in nonpalpable breast cancers [14]. Chao et al. [15] showed in a large database of patients who received sentinel lymph node biopsy that palpability was an independent risk factor for nodal metastasis. They explained that palpable breast cancers were located closer to the skin which has abundant dermal lymphatics. In the present study, palpable breast cancers tended to have positive lymph node metastasis. However, according to a multivariate analysis, a significant difference was not observed between the groups. This discrepancy is possibly attributed to the fact that possibly attributed to the fact that palpability was not only associated with the superficial location.

Hormone receptor status is the most important prognostic factor for breast cancer. Li Z et al. [17] reported that breast cancers positive for both ER and PgR had more favorable prognosis than breast can- cers positive for either ER or PgR. Furthermore, a previous study reported that nonpalpable breast cancers were more likely to be positive for hormone receptor [14]. In the present study, nonpalpable breast cancers tended to be ER and/or PgR-positive and HER-2 negative subtypes. Additionally, palpable breast cancers tended to be TNBCs, which showed a significant difference. However, according to a multivariate analysis, it was not associated with palpability, suggesting that palpability was the independent prognostic factor for breast cancer regardless of the ER, PgR or HER-2 status.

The present study is considered unique and significant because this study compares palpable breast cancers and nonpalpable breast cancers and based on the result of the present study, palpable breast cancers had a higher histologic grade and a Ki-67 index than nonpalpable breast cancers, which was associated with tumor aggressiveness. According to a previous study, neoadjuvant chemotherapy induced a change in the hormone receptor from negative to positive, decreased Ki-67 index, and improved clinical outcomes [18]. These changes influenced the prognosis of breast cancers. However, the mechanisms underlying the hormone receptor status and the Ki-67 index change as the cancer grows remain unclear. This study initially assessed the Ki-67 index suggesting that a higher Ki-67 index might be verified initially in palpable breast cancers or an increasing tumor size might increase the Ki-67 index.

However, apart from the above-mentioned findings, palpable breast cancers initially have a higher Ki-67 index and poorer prognosis than nonpalpable breast cancers. Therefore, careful attention should be paid to the management of palpable breast cancers.

The role of breast physical examination in breast cancer diagnosis has been of little importance. Furthermore, the function of breast examination for screening has not been paid significant attention. However, palpability could be considered a prognostic factor for breast cancers detected at annual check-ups. In the present study, palpability was considered an evident prognostic factor for breast cancers. The clinical course and outcome of breast cancers can be anticipated based on palpation before deciding on surgery and treatment plan.

Our study has some limitations. First, this was a retrospective study that used medical records from multiple centers. Second, palpability is a significantly subjective concept. Although we defined palpability based on physicians' physical breast examinations, palpability may be either over-diagnosed or under diagnosed. Furthermore, palpability 
might be influenced by several factors. The ratio of breast cancer and total breast volume should be evaluated through radiologic methods and by paying careful attention to changing characteristics such as the hormone receptor status and $\mathrm{Ki}-67$ index according to the increasing tumor size.

Palpable breast cancers tend to be TNBCs and have a higher histologic grade and Ki-67 index than nonpalpable breast cancers. Additionally, palpable breast cancers have more aggressive features and worse prognoses than nonpalpable breast cancers. Therefore, the present study findings suggest that treating palpable breast cancers requires careful attention.

\section{CONFLICT OF INTEREST}

The authors declare that they have no competing interests.

\section{ACKOWLEDGMENTS}

This article was supported by the Korean Breast Cancer Society.

\section{REFERENCES}

1. Independent UK panel on breast cancer screening. The benefits and harms of breast cancer screening: an independent review. Lancet 2012;380:1778-86.

2. Myers ER, Moorman P, Gierisch JM, Havrilesky LJ, Grimm LJ, Ghate $\mathrm{S}$, et al. Benefits and harms of breast cancer screening: a systematic review. JAMA 2015;314:1615-34.

3. Jorgensen KJ, Gotzsche PC. Overdiagnosis in publicly organised mammography screening programmes: systematic review of incidence trends. BMJ 2009;339:b2587.

4. Kalager M, Adami HO, Bretthauer M, Tamimi RM. Overdiagnosis of invasive breast cancer due to mammography screening: results from the Norwegian screening program. Ann Intern Med 2012;156: 491-9.

5. Bjurstam N, Bjorneld L, Warwick J, Sala E, Duffy SW, Nystrom L, et al. The Gothenburg breast screening trial. Cancer 2003;97:2387-96.

6. Moss SM, Wale C, Smith R, Evans A, Cuckle H, Duffy SW. Effect of mammographic screening from age 40 years on breast cancer mortality in the UK age trial at 17 years' follow-up: a randomised con- trolled trial. Lancet Oncol 2015;16:1123-32.

7. Kim I, Kang BS, Kim SK. Clinicopathologic characteristics of malignant nonpalpable breast lesions with microcalcification compared to the benign group. J Breast Dis 2014;2:16-21.

8. Min SY, Kim Z, Hur MH, Yoon CS, Park EH, Jung KW, et al. The basic facts of Korean breast cancer in 2013: results of a nationwide survey and breast cancer registry database. J Breast Cancer 2016;19: 1-7.

9. Park EH, Min SY, Kim Z, Yoon CS, Jung KW, Nam SJ, et al. Basic facts of breast cancer in Korea in 2014: the 10-year overall survival progress. J Breast Cancer 2017;20:1-11.

10. Skinner KA, Silberman H, Sposto R, Silverstein MJ. Palpable breast cancers are inherently different from nonpalpable breast cancers. Ann Surg Oncol 2001;8:705-10.

11. Warren SL, Bhutiani N, Agle SC, Martin RCG, McMasters KM, Ajkay N. Differences between palpable and nonpalpable tumors in early-stage, hormone receptor-positive breast cancer. Am J Surg 2018;216:326-30.

12. Kwan ML, Chen WY, Kroenke CH, Weltzien EK, Beasley JM, Nechuta SJ, et al. Pre-diagnosis body mass index and survival after breast cancer in the after breast cancer pooling project. Breast Cancer Res Treat 2012;132:729-39.

13. Niraula S, Ocana A, Ennis M, Goodwin PJ. Body size and breast cancer prognosis in relation to hormone receptor and menopausal status: a meta-analysis. Breast Cancer Res Treat 2012;134:769-81.

14. Silverstein MJ, Skinner KA, Lomis TJ. Predicting axillary nodal positivity in 2282 patients with breast carcinoma. World J Surg 2001;25: 767-72.

15. Chao C, Edwards MJ, Abell T, Wong SL, Simpson D, McMasters KM. Palpable breast carcinomas: a hypothesis for clinically relevant lymphatic drainage in sentinel lymph node biopsy. Breast J 2003;9: 26-32.

16. Olivotto IA, Jackson JS, Mates D, Andersen S, Davidson W, Bryce CJ, et al. Prediction of axillary lymph node involvement of women with invasive breast carcinoma: a multivariate analysis. Cancer 1998; 83:948-55.

17. Li Z, Tu Y, Wu Q, Wang Z, Li J, Zhang Y, et al. Clinical characteristics and outcomes of single versus double hormone receptor-positive breast cancer in 2 large databases. Clin Breast Cancer 2020;20:e15163. 
18. Rossi L, Verrico M, Tomao S, Ricci F, Fontana A, Spinelli GP, et al. Expression of ER, PgR, HER-2, and Ki-67 in core biopsies and in definitive histological specimens in patients with locally advanced breast cancer treated with neoadjuvant chemotherapy. Cancer Chemother Pharmacol 2020;85:105-11. 